Bulletin d'Histoire Contemporaine de l'Espagne

$51 \mid 2017$

Les forces politiques durant la Seconde République espagnole

\title{
Alejandro Quiroga Fernández De Soto, Goles y banderas. Fútbol e identidades nacionales en España
}

Julián Vadillo Muñoz

\section{CpenEdition}

\section{Journals}

Edición electrónica

URL: http://journals.openedition.org/bhce/808

DOI: $10.4000 /$ bhce.808

ISSN: 1968-3723

\section{Editor}

Presses Universitaires de Provence

Edición impresa

Fecha de publicación: 1 junio 2017

Paginación: 345-348

ISSN: 0987-4135

\section{Referencia electrónica}

Julián Vadillo Muñoz, «Alejandro Quiroga Fernández De Soto, Goles y banderas. Fútbol e identidades nacionales en España », Bulletin d'Histoire Contemporaine de l'Espagne [En línea], 51 | 2017, Publicado el 09 octubre 2018, consultado el 24 septiembre 2020. URL : http://journals.openedition.org/bhce/808 DOI : https://doi.org/10.4000/bhce.808 
La monografía plantea, por tanto, una extensión de la política franquista hacia el amplio sector editorial. Se advierte en ella el modo en que el franquismo es coherente en todas sus actuaciones: desde el libro a la economía, la política exterior, los medios de comunicación, la cultura o la sociedad. Todos los ámbitos de la vida nacional sufrieron dichas actuaciones que podríamos resumir en la coerción, el intervencionismo, la censura, la vigilancia, el control y el apartamiento del diferente. En definitiva, la implantación de un régimen impositivo y represor cuyo objetivo era el establecimiento de un modelo de sociedad sometido a la disciplina, el orden y la unidad, unos principios de inspiración ultra conservadora tomados del tradicionalismo español. Los especialistas del franquismo podrán ver en la publicación una pieza importante de la articulación de este modelo social que complementa las investigaciones de otros aspectos culturales y mediáticos del primer franquismo.

Matilde EIROA

Universidad Carlos III de Madrid

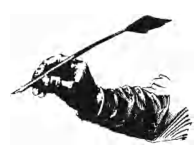

\section{Alejandro QUIROGA FERNÁNDEZ DE SOTO}

Goles y banderas. Fútbol e identidades nacionales en España, Madrid, Marcial Pons, 2014.

Muchas veces habremos oído aquello de «el fútbol no es importante». Sin embargo estamos hablando de un deporte que cuenta con millones de aficionados y casi igual número que lo práctica en distintas categorías. Luce más hacer un trabajo de investigación sobre un rey o un movimiento político concreto que sobre un equipo de fútbol o algo relacionado con el deporte. Y eso es injusto. Sobre todo porque hay importantes trabajos de investigación que tienen al deporte como eje central y aportan mucho a la materia humanística.

El libro de Alejandro Quiroga entraría dentro de esos trabajos de investigación que aportan un gran valor a la ciencia histórica tratando un tema de esos que algunos denominan «poco serios» y que para nada lo son.

Sobre fútbol se han escrito varias cosas. Desde historias de algunos de los equipos de fútbol más emblemáticos hasta la relación del fútbol como movimientos como el obrero. En estos aspectos hay que destacar obras como la de Eduardo Galeano El futbol a sol y sombra, donde de una forma sencilla nos acerca a algunas curiosidades futbolísticas de un aficionado a este deporte como Galeano. O el más reciente de Quique Peinado Futbolistas de izquierdas donde en un buceo de documentación se cuenta alguno de los casos más carismáticos de gente del mundo del fútbol comprometida con la izquierda política (Sócrates, Breitner, Lucarelli, etc.)

Tampoco sorprende como en los estudios sobre el movimiento obrero aparecen en muchas ocasiones equipos de fútbol fundados por anarquistas o socialistas. Destacaríamos como el actual Argentinos Juniors se llamaba «Mártires del Primero del Mayo». También como la camiseta de equipos como New's Old Boys argentino o el Basañez uruguayo tienen el color rojinegro en su camiseta por estar impulsado por anarquistas. O el equipo croata del Hajduk Split recibió al principio el nombre de «Anarkho».

También ha sido común encontrarse en algunas historias sociales la enormes relaciones que el obrerismo ha tenido con el deporte en su conjunto. Son varios de los ejemplos 
de grupos excursionistas, grupos de atletismo, etc. Por ejemplo los núcleos de la CNT de Alcalá de Henares nacieron al calor de una asociación deportiva, la Unión Ciclista Alcalaína. Los socialistas desarrollaron números grupos deportivos y en Guadalajara llegaron a editar un periódico con el nombre La zancadilla. No podemos olvidar que en Madrid se jugaba durante los años treinta una Liga Obrera de fútbol donde estaban equipos como el Rayo Vallecano.

Interesante sería también hacer un estudio sobre la división sociológica de los aficionados a los equipos de fútbol. No es extraño encontrar en la documentación de militantes socialistas y anarquistas del barrio de Cuatro Caminos y Tetuán en Madrid carnets del Atlético de Madrid, equipo del barrio madrileño. O como directivas del Real Madrid o del Barcelona tenían una fuerte vinculación republicana durante los años treinta. Incluso el presidente del FC Barcelona, Josep Sunyol i Garriga fue detenido y fusilado en la Sierra de Guadarrama por los golpistas en agosto de 1936.

Pero el libro de Alejandro Quiroga da un paso más a este respecto. En una perfecta comunión de interdisciplinariedad, Alejandro Quiroga vincula la práctica y afición del fútbol a la creación de las identidades nacionales. Un estudio histórico, sociológico y antropológico de gran valía.

El eje básico del libro es comprobar cómo alrededor de la selección española de fútbol se ha ido generando todo un discurso nacionalista así como el fomento de la identidad nacional. La creación de unas señas de identidad de la seleceión española desde su denominación de las Olimpiadas de Amberes de 1920 de la «furia española» hasta «La Roja» triunfante en las Eurocopas de 2008 y 2012 y el Mundial de Sudáfrica de 2010.

Dos leitmotivos movieron a la selección española durante muchas décadas: por una parte, el coraje y la furia por conseguir lo imposible (el autor pone un interesante ejemplo de cómo trató la prensa algunos resultados de la selección), por otra, el victimismo y la mala suerte, que responsabilizaron constantemente a los árbitros de los malos resultados. Esta imagen hizo fortuna en España pero fue contraproducente a nivel internacional porque fue tomada por la prensa extranjera, que siempre presentó a los españoles como rudos, hoscos. No fue extraño que a lo largo de los años hubiese disputas en la prensa entre España y otros países como Francia o Inglaterra. Las referencias al pasado histórico de las naciones era común. La Armada Invencible, la leyenda negra y demás cuestiones saltaban a primera páginas de los periódicos de la forma más sensacionalista.

Algo que Alejandro Quiroga aborda de forma brillante es la instrumentalización que el franquismo realizó de la selección española. A pesar de que muchos exiliados iban a ver a la selección en los partidos que jugaban en el extranjero (también a otros equipos) y fue siempre un núcleo de unión entre los propios españoles, el franquismo instrumentalizó el fútbol como adoctrinamiento. Personajes como el general Moscardó, que fue Delegado Nacional de Deportes, contribuyeron mucho a esta faceta. Incluso tras el cuarto puesto de España en el Mundial de Brasil de 1950, hizo que Franco se apropiase de la victoria. De estos años viene la asimilación del Real Madrid como equipo proclive a la dictadura. Destaquemos lo dicho anteriormente. Los republicanos exiliados acudían a partidos de la selección española con banderas republicanas, convirtiéndose el fútbol en una identidad común de esa parte de España fuera de sus fronteras.

El clímax de esta asimilación se produjo con la victoria española en la Eurocopa de 1964 contra la URSS. Vencer a la Unión Soviética fue vendido por el franquismo como una nueva derrotada en el campo de batalla frente al «enemigo» comunista. Además esa victoria coincidió con los llamados 25 años de Paz y con otras victorias deportivas de 
los españoles. Se hizo un hilo de unión entre la épica furia de Amberes hasta la victoria contra la URSS. El partido se repitió de forma constante en la televisión, que comenzaba a proliferar en los hogares españoles.

Importante también es el tema que se aborda con la llegada de la democracia a España. Comenzaron a proliferar prensa deportiva de todo tipo que con las épocas más reciente se convierte en masiva. La prensa hizo un gran despliegue con el Mundial de 1982, mientras la prensa extranjera siempre buscó el error y la corrupción, tan típicas de un país que había heredado esos vicios del franquismo, tal como en más de una ocasión ha remarcado Paul Preston. Una prensa deportiva que en los últimos tiempos ha estado muy marcado por una guerra económica entre las mismas plataformas digitales que controlan la emisión de futbol con implicaciones políticas de primer orden. Incluso es interesante como con el estallido de la crisis económica los gabinetes de Zapatero y Rajoy han mostrado al fútbol como un bálsamo coincidiendo con la época triunfal de la selección española y con la época dorada del futbol español que ha conquistado todos los títulos europeos e intercontinentales (Barcelona, Real Madrid, Sevilla, Atlético de Madrid, etc.)

Muchas más implicaciones aborda Quiroga en el libro, como la misma instrumentalización de la rivalidad entre Real Madrid y Barcelona para la creación de una identidad nacional.

Pero parte importante en libro es como se trata la formación de esa identidad a través de equipos como el FC Barcelona y el Ahtletic Club de Bilbao o la Real Sociedad de San Sebanstián. A nivel de Cataluña el Barcelona siempre fue desde el inicio un motor que unió la identidad catalana. Ya hemos señado como incluso un presidente del Barcelona fue asesinado por lo militares rebeldes en 1936. Durante el franquismo el Barcelona siempre se vio como un club que guardaba las esencias catalanas, el refugio de un nacionalismo catalán que había sido derrotado tras la guerra. Sin embargo Alejandro Quiroga también muestra como durante el franquismo también hubo «concesiones» por parte del régimen dietatorial. En ciclismo se siguió denominando «Volta Cataluña» a la ronda catalana. Esa guerra de presentar al Barcelona como el elemento del nacionalismo venía de muy atrás. El Barcelona había nacido en 1899 y un año después nacía el Real Club Deportivo Español de Barcelona que nacía para competir en esencia y exitencia todo lo que rodeaba al club azulgrana. Aunque por aquellos también exitían equipos como el Español de Madrid.

Sin embargo los años finales de la dictadura presentan a un Barcelona combativo por la nacionalidad catalana, por sus símbolos y colores. Algo que presentaba al Barcelona como una entidad que en la clandestinidad mantuvo unido los sentimientos del catalanismo. La prensa catalana comenzó a presentar al Barcelona como el equipo de la descentralización y la modernidad democrática frente al Real Madrid concebido como un equipo centralista y autoritario. Numerosos políticos de distintas tendencias mostraron sus simpatías y eran socios del FC Barcelona. El Español también fue entrando en la dinámica de presentarse como un equipo catalán y de «catalanidad», aunque de forma mucho más tardía.

El País Vasco tuvo una evolución un tanto distinta. En los orígenes el fútbol no significó tanto un vehículo de socialización y unión de los vascos. Más bien miraban a otros deportes o tradiciones. Sin embargo, paulatinamente, el Athletic Club y la Real Sociedad fueron concebidos y presentados durante tiempo, al igual que el Barcelona, como los equipos del nacionalismo vasco. Aun así durante el franquismo también hubo peculiaridad. Mientras el resto de equipos, junto con los jugadores de sus canteras fichaban a jugadores de primer orden mundial, el Athletic solo jugaba con jugadores salidos de su cantera. Esto hizo que el franquismo presentara el fútbol de Athletic como el verdaderamente español. 
A pesar de ello jugadores y directivos se fueron vinculando o acercando a los movimientos políticos de independentistas vascos. No dejó de ser impactante ver a un jugador como Iribar sentarse en la Mesa Nacional de Herri Batasuna (HB) una vez que Franco murió. Fueron jugadores que apoyaban el movimiento vasco independentista pero que se alejaron de la violencia terrorista de ETA en los años sucesivos. Grabada queda también la imagen de los jugadores de la Real Sociedad y del Athletic de salir en el antiguo campo de Atocha con la ikurriña cuando estaba aun prohibida.

El libro de Alejandro Quiroga logra demostrar como aficionados, gente en general se sienten vinculados a una idea nacional a un concepto de identidad a traves del fútbol. Lo que hace que este deporte tenga muchas más aristas de análisis de las que se quieren mostrar en muchas ocasiones. La obra de Quiroga gira en torno a tres ejes:

1. Una narrativa nacional determinada por el contexto histórico en el que se genera. Fundamental para entenderla en su justa medida. No es lo mismo analizar a la selección española en la década de 1950 que hacerlo en la actualidad.

2. Una narrativa surgida de la imagen futbolística de España en la prensa española e internacional. Para unos España era victima de injusticias. Para otro el fútbol de España era tosco y típico del carácter español.

3. Un paralelismo entre lo que sucede en España y en el resto del mundo. Lo que pasa en las fronteras nacionales españoles no es exclusivo de aquí. Se comprueba viendo como paises como Argentina o Francia viven y encarna su sentimiento nacional a través de su selección de fútbol.

La obra de Quiroga viene a completar, con otro tema, su buen bagaje investigador en los nacionalismos y las identidades nacionales, de las que ya dio buena cuenta en obras como Los orígenes del nacionalcatolicismo, Haciendo españoles. La nacionalidad de las masas en la dictadura de Primo de Rivera (1923-1930) y la conjunta con Sebastian Balfour España reinventada. Nación e identidad desde la Transición. Este Goles y banderas. Fútbol e identidades nacionales en España no dejará indiferente a aficionados o profanos al deporte futbolístico. 